\title{
The rescheduling system for trains, drivers and crew of high speed railways
}

\author{
H. Shimizu ${ }^{1}$, H. Tanabe ${ }^{2}$ \& M. Matsumoto ${ }^{2}$ \\ ${ }^{1}$ JR East Japan Information Systems Company, Japan \\ ${ }^{2}$ East Japan Railway Company, Japan
}

\begin{abstract}
We are developing the new rescheduling system for drivers and crew that synchronizes the train forecasted plan. The East Japan Railway Company has five Bullet Train lines (SHINKANSEN) operating about 800 trains per day, and dispatching nearly 250 drivers and 350 crew per day in order to operate the trains. To keep the operation plan and management of SHINKANSEN properly, we have the system named COSMOS (Computerized Safety Maintenance and Operation systems of SHINKANSEN). The drivers and crew rostering schedule are made with the drivers and crew rescheduling system that is one of the subsystems of COSMOS Transportation Planning System. Each driver and crew works on their trains according to a rostering scheduling decided upon beforehand normally. However, sometimes trains would be unable to operate on schedule when the weather is bad or car troubles happen. In such cases, the rostering scheduling must be redesigned. The influence reaches the two or more crews' rostering scheduling by changing only one crew member. It is very difficult to make this rescheduling because a delay of the train changes minute by minute. To make the crews' rostering scheduling change adequately, we have developed a new system. This system displays some contradictions of the rescheduled plan of drivers and crew if a train delay happened. Dispatchers reschedule the plan to solve these contradictions.

We reduce the delay time of trains by utilizing this system and will improve our services for customers.
\end{abstract}

Keywords: train traffic rescheduling, drivers rostering rescheduling, crew rostering rescheduling, forecast, real-time rescheduling. 


\section{Introduction}

East Japan Railway Company (JR-East) has five Bullet Train (SHINKANSEN) lines - Tohoku line, Joetsu line, Hokuriku line, Yamagata line, and the Akita line.

Our network of SHINKANSEN is shown in Figure 1, and features of each line are shown in Table 1 . These lines all start from Tokyo and directly connect to five areas in east Japan.

A part of the section of the Yamagata line - between Fukushima and Shinjo and a part of section of the Akita line - between Morioka and Akita are low speed sections. In these sections, SHINKANSEN trains and local trains are operated in coexistence. Trains of Yamagata and Akita line are combined with the train of Tohoku line between Tokyo and Fukushima or between Tokyo Morioka.

To respond to a variety of passenger needs in the SHINKANSEN transportation, JR-East has a variety of types of cars. The types of vehicles in April, 2010 are shown in Table 2. The transportation scale, the number of trains per day, car rostering, driver rostering and crew rostering are shown in Table 3.

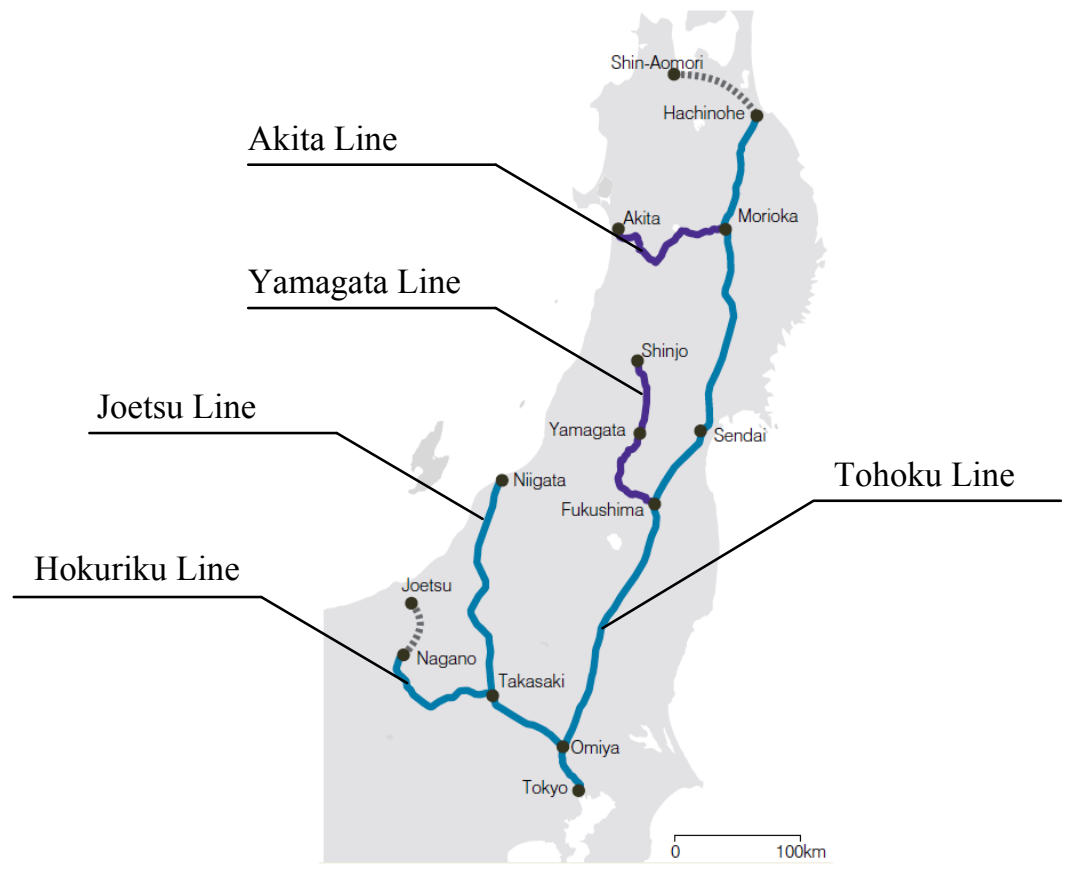

Figure 1: $\quad$ Network of JR-East SHINKANSEN [3]. 
Table 1: $\quad$ Features of JR-East SHINKANSEN (As of March 2010).

\begin{tabular}{|l|l|l|c|}
\hline Line name & Distance of line & Name of trains & $\begin{array}{l}\text { Number a } \\
\text { day of trains }\end{array}$ \\
\hline Tohoku Line & $\begin{array}{l}631.9 \mathrm{~km} \\
\text { (Tokyo - Hachinohe) }\end{array}$ & Yamabiko & 89 \\
\cline { 3 - 4 } & & Hayate & 37 \\
\cline { 3 - 4 } & Nasuno & 38 \\
\hline Joetsu Line & $\begin{array}{l}333.9 \mathrm{~km} \\
\text { (Tokyo - Niigata) }\end{array}$ & Toki & 56 \\
\cline { 2 - 4 } & Tanigawa & 39 \\
\hline Hokuriku Line & $\begin{array}{l}\text { 222.4 km } \\
\text { (Tokyo - Nagano) }\end{array}$ & Asama & 56 \\
\hline Yamagata Line & $\begin{array}{l}\text { 421.4 km } \\
(\text { Tokyo - Shinjo) }\end{array}$ & Tsubasa & 33 \\
\hline Akita Line & $\begin{array}{l}662.6 \mathrm{~km} \\
(\text { Tokyo - Akita) }\end{array}$ & Komachi & 32 \\
\hline
\end{tabular}

Table 2: $\quad$ Kinds of vehicles of JR-East SHINKANSEN (As of March 2010).

\begin{tabular}{|l|l|l|l|l|}
\hline Type & $\begin{array}{l}\text { Name of } \\
\text { vehicle }\end{array}$ & $\begin{array}{l}\text { Line chiefly } \\
\text { operated }\end{array}$ & Car type & $\begin{array}{l}\text { Partner of } \\
\text { combining }\end{array}$ \\
\hline 200 & K & Joetsu & 10 cars, Flat & None \\
\hline E1 & M & Joetsu & 12 cars, Duplex & Enable \\
\hline E2 & J & $\begin{array}{l}\text { Tohoku, } \\
\text { Joetsu }\end{array}$ & 10 cars, Flat & R \\
\cline { 2 - 5 } & N & Hokuriku & 8 cars, Flat & Enable \\
\hline E3 & R & Akita & 6 cars, Flat & J \\
\cline { 2 - 5 } & LR & Yamagata & 7 cars, Flat & P \\
\hline E4 & P & $\begin{array}{l}\text { Tohoku, } \\
\text { Joetsu }\end{array}$ & 8 cars, Duplex & P, LR \\
\hline E5 & Unsigned & Tohoku & 10 cars, Flat & Undecided \\
\hline
\end{tabular}

Table 3: $\quad$ The transportation scale of JR-East SHINKANSEN.

\begin{tabular}{|l|c|}
\hline Trains & About 1,000 \\
\hline Car rostering & About 200 \\
\hline Driver rostering & About 250 \\
\hline Crew rostering & About 350 \\
\hline
\end{tabular}

\section{The transportation feature in JR-East SHINKANSEN}

There are following three large transportation features in JR-East SHINKANSEN. 
(1) All trains of five lines and share limited track capacity between Tokyo and Oomiya.

(2) To operate many trains five lines in limited track capacity, some of them are combined with another.

(3) There is a difference at the transportation stability level between SHINKANSEN line and conventional line, and a conventional line train delay might influence SHINKANSEN trains.

There is the possibility of influencing all areas and all trains even if a delay occurs in a small area. Therefore, we need to reschedule the plan of train operation as soon as possible.

For example, in conventional sections between Fukushima and Yamagata of Yamagata line, a delay of trains and operation suspension of trains occur owing to rainfall or snowfall and so on.

If a delay of trains of Yamagata occurs, it influences combined trains of Tohoku. In this case, we reschedule a splitting and combining plan of trains of Yamagata line and Tohoku line. It is a simple solution that all splitting and combining plans are cancelled and each train is operated by itself. But there are the following problems.

(1) An unscheduled driver and crew is needed.

(2) It is difficult that we add trains to the section between Tokyo and Omiya limited line capacity.

To avoid these problems, we change combined partner trains one by one. It is called "DAN-OCHI" in Japanese.

One of the examples of this rescheduling is shown in figure 2.
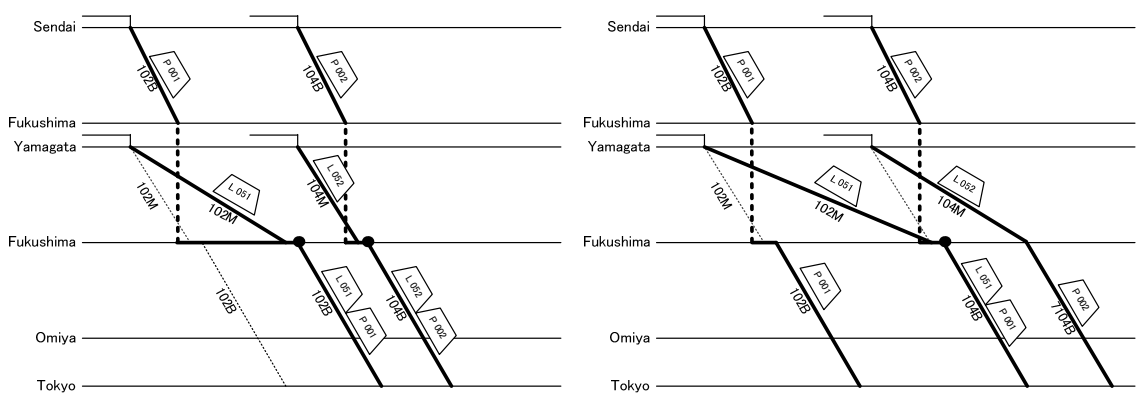

Figure 2: $\quad$ One of examples of combining plan rescheduling.

\section{COSMOS overview}

\subsection{General overview}

In an operation of JR-East SHINKANSEN, we need to reschedule the train operation plan as soon as possible. Therefore, we have some systems called "COSMOS" for supporting our judgement of rescheduling. COSMOS has eight systems - Transportation Plan System, Operation Control System, Rolling Stock Control System, Facility Control System, Maintenance Work Control System, 
Railway Yard Work Management System, Facility Monitoring System and Electric Power Control System. We are highly managing and controlling information of transportation of SHINKANSEN by cooperatively using these eight systems. Systems overview is shown in Figure 3.

In this thesis, the sub-system that the drivers and crew use in the rescheduling system which is one of sub-systems of the Transportation Plan System, cooperates with the train traffic rescheduling system which is one of sub-systems of the Operation Control System is described. The overview of two systems is shown in Figure 4. This development overview of two systems was reported in our thesis [1]. This drivers and crew rescheduling system came into practical use beginning in March, 2009.

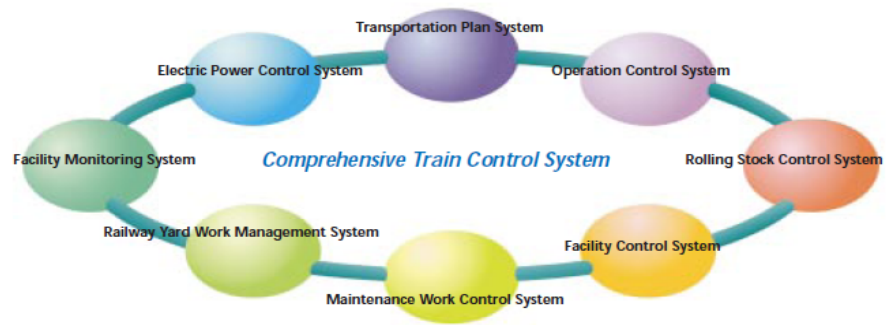

Figure 3: Overview of COSMOS systems.

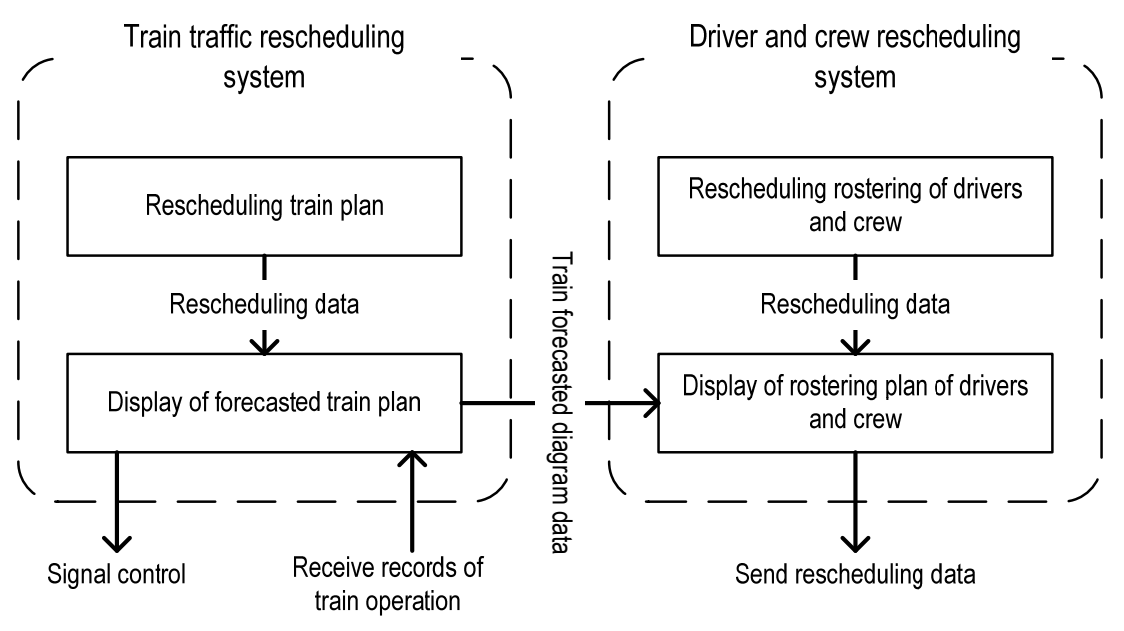

Figure 4: Cooperation between rescheduling functions.

\subsection{Effect of improvement}

We remade and began to use the COSMOS Transportation Planning System and Operation Control System in May, 2008. In this renewal, we redesigned some 
input window and input flow of train traffic rescheduling system. Consequently, we achieved the effect shown in Table 4 . The average input time has shortened two minutes or more before and after the function improvement. Because it is necessary to input a lot of train traffic rescheduling, an effect of this time crunch is large.

Table 4: $\quad$ The average input time.

\begin{tabular}{|l|c|c|c|c|}
\hline & \multicolumn{2}{|c|}{ Number of input times } & \multicolumn{2}{c|}{ Average input time } \\
\cline { 2 - 5 } & Before & After & Before & After \\
\hline $\begin{array}{l}\text { Window 1 } \\
\text { (Run alone) }\end{array}$ & 2 & 1 & $1 \mathrm{~min} 38 \mathrm{sec}$ & $54 \mathrm{sec}$ \\
\hline $\begin{array}{l}\text { Window 2 } \\
\text { (Change } \\
\text { combined } \\
\text { partner) }\end{array}$ & 4 & 2 & $2 \mathrm{~min} 36 \mathrm{sec}$ & $1 \mathrm{~min} 52 \mathrm{sec}$ \\
\hline $\begin{array}{l}\text { Window 3 } \\
\text { (Cancel to } \\
\text { combine) }\end{array}$ & 7 & 3 & $4 \mathrm{~min} 37 \mathrm{sec}$ & $2 \mathrm{~min} 27 \mathrm{sec}$ \\
\hline $\begin{array}{l}\text { Example } \\
\text { input } \\
\text { rescheduling } \\
\text { shown in }\end{array}$ & 8 & 4 & $5 \mathrm{~min} 52 \mathrm{sec}$ & $3 \mathrm{~min} 40 \mathrm{sec}$ \\
Figure 2
\end{tabular}

\section{Case study}

\subsection{The train traffic rescheduling system}

This chapter introduces the train traffic rescheduling system which is one of the sub-systems of the COSMOS Operation Control System.

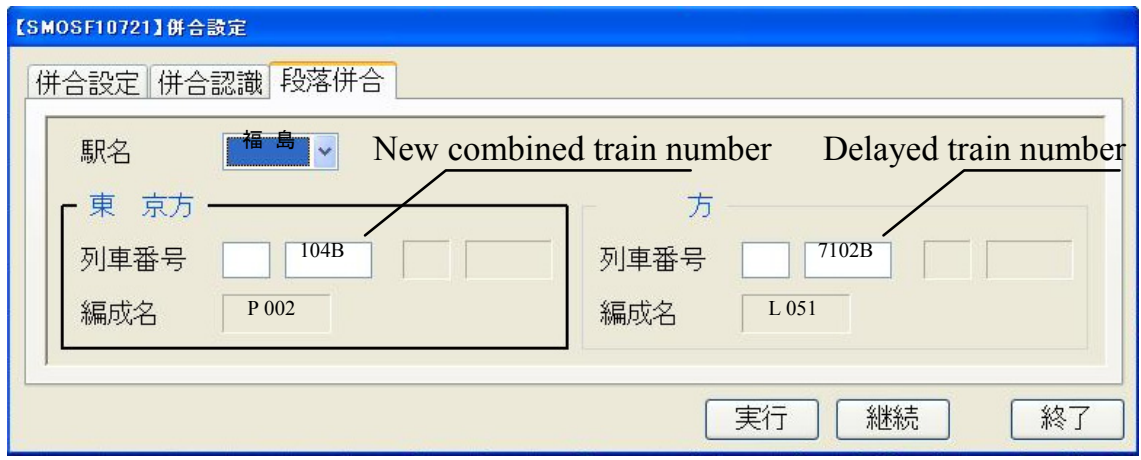

Figure 5: $\quad$ Input window of system. 


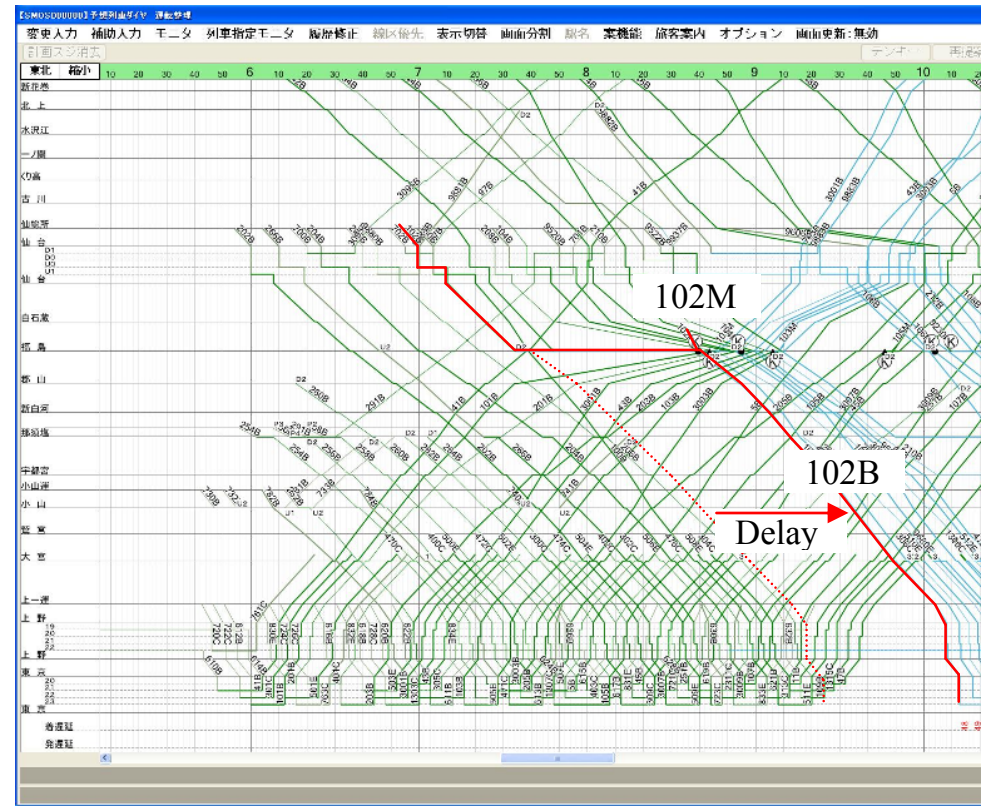

Figure 6: Train forecasted diagram before rescheduling.

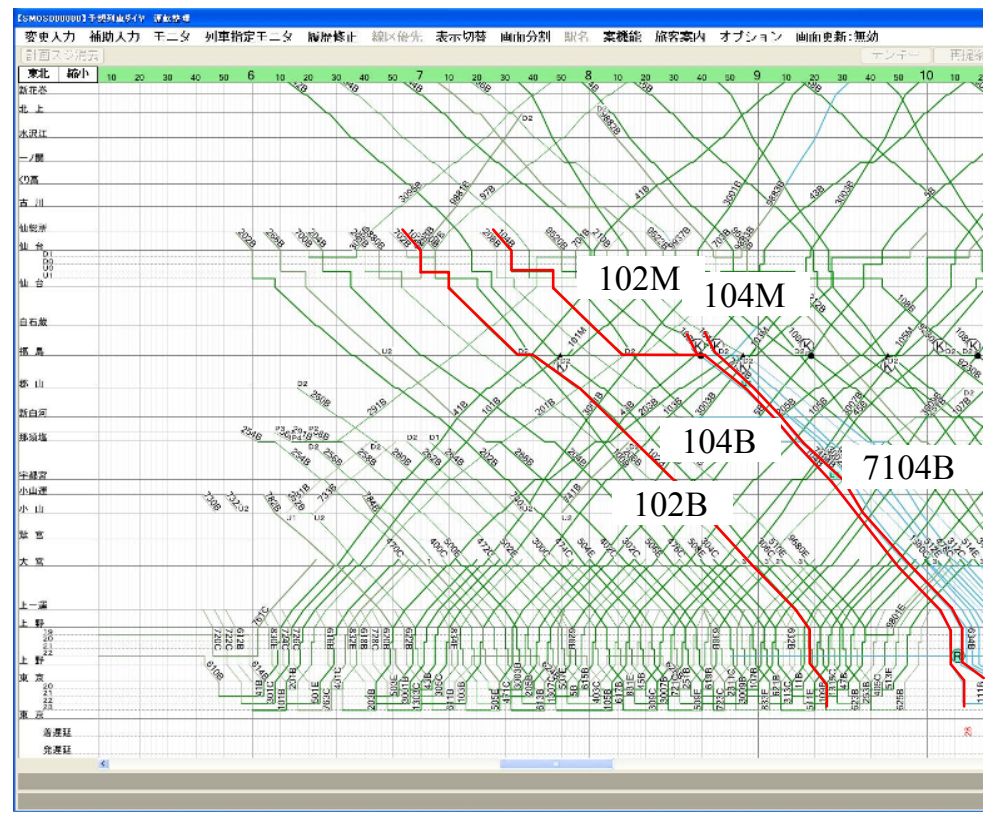

Figure 7: $\quad$ Train forecasted diagram after rescheduling. 
If a delay occurs in a conventional section, we need to reschedule the train operation plan as soon as possible. For example, when there is a delay of train number "102M" between Yamagata and Fukushima, we reschedule train traffic using the input window of the system which is shown in Figure 5, and a train forecasted diagram before rescheduling is shown in Figure 6. A train forecasted diagram after rescheduling is shown in Figure 7.

Train "102M" is combined with "102B" at Fukushima. "102M" is assigned car "L 051 ". In this case, we change the combined partner of " $102 \mathrm{M}$ " from "102B" to "104B", and we change combined partner of "104M" from "104B" to none. "104M" is operated alone as train number "7104B" from Fukushima to Tokyo.

\subsection{The drivers and crew rescheduling system}

When train traffic is rescheduled, the driver and crew rostering plan is influenced, and we have to reschedule the rostering plan using the drivers and crew rescheduling system.

This chapter introduces the drivers and crew rescheduling system which is one of the sub-systems of COSMOS Transportation Plan System. In this subsystem, the forecasted driver and crew rostering diagrams and some contradictions are displayed in a window. This forecasted rostering scheduling is created based on a train forecasted diagram data. Dispatchers monitor this window and input the changing data of rescheduling to the system.

For example, when there is a delay of train number " $102 \mathrm{M}$ " between Yamagata and Fukushima, we reschedule drivers rostering plan using the input window which is shown in Figure 8, and the drivers forecasted diagram before rescheduling is shown in Figure 9-left figure. The drivers' forecasted diagram after rescheduling is shown in Figure 9-right figure.

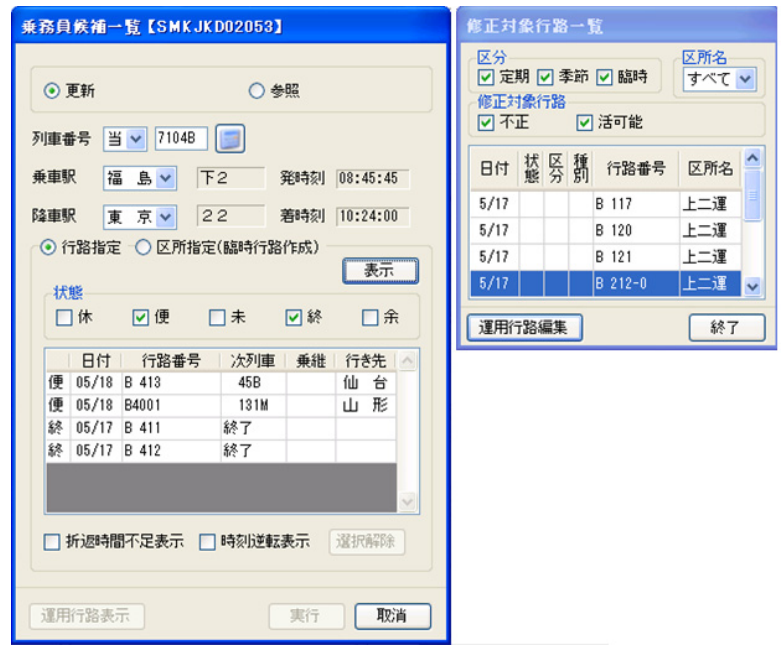

Figure 8: $\quad$ Input window of system. 

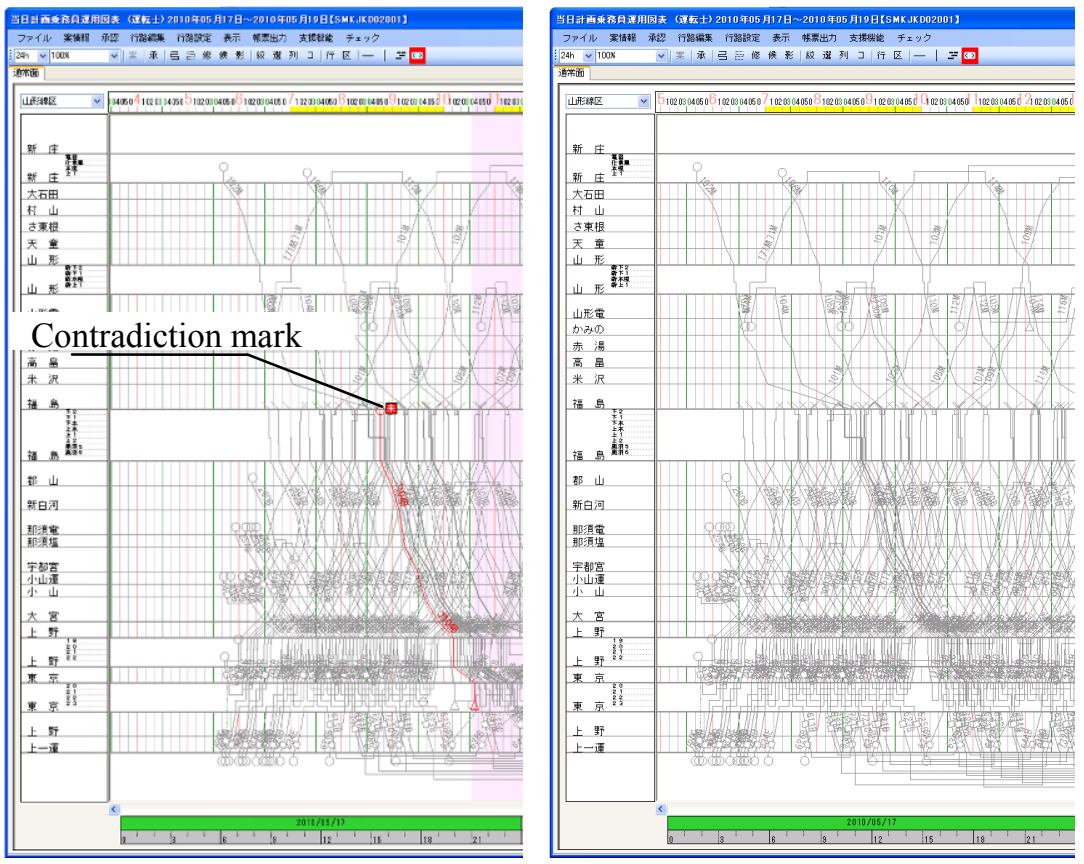

Figure 9: $\quad$ Drivers forecasted diagram before and after rescheduling.

\section{Conclusion}

In this thesis, the features in JR-East SHINKANSEN and supporting systems for train rescheduling and drivers rescheduling are shown.

When the train traffic rescheduling system and the drivers and crew rescheduling system are not used, the planners and the dispatchers have planned by using the paper diagram by their knowledge, experience, and capability.

After these systems have started to be used, we can quickly reschedule train traffic and drivers and crew rostering. In addition, these systems led to the revolution of the drastic business rule of rescheduling of drivers and crew rostering. Dispatchers changed from a person at the center to a local person.

These systems are contributing to the stability improvement of transportation. JR-East thinks our supporting systems to be important and will develop a further upgrade with JR East Japan information systems Company.

We have now been developing the proposal system for SHINKANSEN using constraint programming [2] as one of the upgrades of the train rescheduling system for practical use.

After this proposal system is put to practical use, we expect that we will achieve a higher effect by cooperating with the rescheduling system for drivers and crew. 
680 Computational Methods and Experimental Measurements XV

\section{References}

[1] Hiroyuki SHIMIZU, Hitoshi TANABE, Satoshi HONDA, Kazutoshi YASURA "The new Shinkansen rescheduling system for drivers and crew", Proceedings of Computer System Design and Operation in the Railway and Other Transit Systems - Computers in Railways X, pp. 227-234, (2006)

[2] Hiroyuki SHIMIZU, Hitoshi TANABE, Masashi YAMAMOTO, "The proposal system for Shinkansen using Constraint Programming", Proceedings of World Congress on Railway Research 2008, O.1.3.2.3, (2008)

[3] East Japan Railway Company "2009 Annual Report", http://www.jreast.co.jp/e/investor/ar/2009/index.html 